\title{
The activity of G-ROS and the predominant role of Type II reaction in the photodynamic therapy using 9-hydroxypheophorbide-a for HeLa cell lines
}

\author{
Jin-Chul Ahn ${ }^{1}$ and Phil-Sang Chung ${ }^{1,2}$ \\ ${ }^{1}$ Medical Laser Research Center, Dankook University, Cheonan, Chungnam 330-714, Korea \\ ${ }^{2}$ Department of Otolaryngology-Head and Neck Surgery, Dankook University, Cheonan, Chungnam 330-714, Korea
}

\begin{abstract}
Photodynamic therapy (PDT) is a treatment modality that destroys the tumor. It activates the photosensitizer with the light of a specific wavelength, where the light is well absorbed by the photosensitizer, thus causing a fatal injury and thereby leading to a tumor necrosis. To date, a hematoporphyrin-derived photosensitizer has been widely used. It is disadvantageous, however, in that it causes a long-term photo-toxicity and has a poor selectivity for the tumor. This had led to the development of a chlorophyll-derived photosensitizer. We conducted this study to elucidate the mechanisms by which the activity of ROS is involved in the PDT using a novel type of chlorophyllderived photosensitizer, 9-hydroxypheophorbide- $\alpha$ (9-HpbD- $\alpha$ ), for the HeLa cell lines. Besides, we also attempted to determine which reaction plays a predominant role in the synthesis of ROS, either Type I reaction or Type II one, when both reactions are involved in the synthesis of ROS during the PDT using 9-HpbD- $\alpha$. Our results showed not only that the activity of ROS is involved in the PDT using 9-HpbD- $\alpha$ in human uterine cervical cancer cell lines but also that the mechanisms of PDT are based on Type II reaction where the singlet oxygen is involved.
\end{abstract}

Key words: Photodynamic therapy - 9-hydroxypheophorbide- $a$ - Reactive oxygen species

\section{Introduction}

Photodynamic therapy (PDT) is a treatment modality that destroys the tumor. It activates the photosensitizer with the light of a specific wavelength, thus causing a fatal injury and thereby leading to a tumor necrosis. Since the 1970s, active studies have been conducted to examine the mechanisms of PDT (Abdulla and Haeger-Aronson 1971; Dougherty et al. 1998). To explain the mechanisms by which PDT shows an anti-cancer effect, the following hypotheses have been proposed:

I. A direct injury to the cancer cells, where the light energy is absorbed by a photosensitizer and then transferred to the oxygen, because of the production of singlet oxygen and oxygen free radicals (Moan et al. 1979);

Correspondence to: Phil-Sang Chung, Department of Otolaryngology-Head and Neck Surgery, Medical Laser Research Center, Dankook University, San \#29 Anseodong, Cheonan, Chungnam 330-714, Korea

E-mail: pschung@dankook.ac.kr
II. The secondary necrosis due to the destruction of blood vessels which are responsible for blood supply to the tumor (Nelson et al. 1987);

III. The involvement of immune system in the tumor cells (Ana et al. 2006).

One of the hematoporphyrin derivatives ( $\mathrm{HpD})$, Photofrin ${ }^{\circledR}$ (porfimer sodium) (Pinnacle Biologics, Inc., USA) is being used as a photosensitizer most widely at the present. Its use as a photosensitizer in a clinical setting has also been approved by the US FDA (Food and Drug Administration). In addition, its scope of application has been gradually increased, however, it is disadvantageous that it causes a long-term photo-toxicity and has a poor selectivity for the tumor (Peng et al. 1997). This had led to the development of chlorophyll derivatives (CpD) for the use as a photosensitizer, and it has a higher degree of reactivity and a rapid in vivo metabolism. To date, many studies have therefore been conducted to examine the physicochemical property of chlorophyll derivatives and their mode of action against the cells (Rosenthal 1991). Among the various types of $\mathrm{CpD}$ which have been developed, $\mathrm{CpD}-\mathrm{A}$ triggers the 
occurrence of photo-reaction in a bound or unbound form with the cells. Particularly in a bound form with the cells, it produces fluorescent or active oxygen in response to the light with a variable degree of wavelength. Thus it is appropriate to select it as a photosensitizer (Lee et al. 1990).

The mechanisms of photodynamic therapy are associated with the synthesis of ROS as follows: i) following the selective irradiation with the light, a photosensitizer is absorbed from the cancer cell or target tissue and then activated; ii) the activation of a photosensitizer induces the generation of reactive oxygen species (ROS) in the presence of oxygen molecule.

There are two mechanisms by which the ROS are produced, and these include Type I and II reactions. In Type I reaction, the ROS are produced by a photosensitizer being involved in the electron transfer system. In Type II reaction, the ROS are produced following the reactions due to the energy transfer. The representative ROS are hydroxyl radical and singlet oxygen (Oleinick and Evans 1998; Dougherty 2002). $\mathrm{D}$-mannitol has been known as one of the representative hydroxyl radical scavengers (Desesso 1994). Of the mechanisms of photodynamic therapy, Type II reaction is referred to as that where the singlet oxygen is produced due to the energy transfer between the activated photosensitizer and the oxygen molecule. Both sodium azide (Grether-Beck, 1996) and reduced glutathione (GSH) are singlet oxygen quenchers (Devasagayam 1991), and they are antioxidants that protect the biological organisms against the singlet oxygen.

With the above background, we conducted this study to elucidate the mechanisms by which the activity of ROS is involved in the PDT using a novel type of chlorophyll-derived photosensitizer, 9-hydroxypheophorbide- $\alpha$ (9-HpbD- $\alpha$ ), for the HeLa cell lines (human uterine cervical cancer cell lines). Besides, we also attempted to determine which reaction plays a predominant role in the synthesis of ROS, either Type I reaction or Type II one, when both reactions are involved in the synthesis of ROS during the PDT using 9-HpbD-a.

\section{Materials and Methods}

\section{Photosensitizer and the light source}

To prepare a photosensitizer, chlorophyll of the algae was converted into the derivatives of 10-hydroxypheophytin a through the oxidative reaction and acid treatment by the Kumho Life and Environmental Science Laboratory in Korea. Then, following an organic synthesis of the derivatives of 10-hydroxypheophytin and 10-hydroxypheophytin- $\alpha$ which were extracted using them as an organic solvent, we used 9-hydroxypheophorbide- $\alpha$ (9-HpbD- $\alpha)$ with which a stable structure and a massive yield could be achieved. For the light source, we used a 670-nm diode laser (Medical Laser Re- search Center, Korea) where a photosensitizer has a maximal phototoxic activity.

\section{Cell culture}

In the current study, we used HeLa cells (KCLB \#100026), human uterine cervical cancer cell lines which were purchased from the Korean Cell Line Bank (KCLB). The cells were cultured in Dulbecco's modified Eagle's medium (DMEM), which was prepared by the addition of $10 \%$ fetal bovine serum (FBS) (GibcoBRL, USA) and antibiotic-antimycotic solution (Gibco, BRL) to the DMEM (GibcoBRL, USA) culture medium. Then, these cells were cultured in a cell culture flask in an incubator (Thermo Forma, USA) where an optimal level of humidity and a temperature of $37^{\circ} \mathrm{C}$ were maintained by supplying a 5\% carbonic acid gas and a 95\% air. The cellular morphology was examined using an inverted microscope (Olympus CK40, Japan). The cells grew while being attached to the floor of flask. Then, the cells were subcultured following the treatment with trypsin (GibcoBRL, USA).

\section{Experimental groups}

The experimental groups included cancer cells treated with:

Group A: the laser

Group B: 9-HpbD-a

Group C: PDT

Group D: D-mannitol (40 or $80 \mathrm{mM}$ ) following the PDT Group E: sodium azide (20 or $40 \mathrm{mM}$ ) following the PDT

Group F: GSH (5 or $10 \mathrm{mM}$ ) following the PDT.

As a control, untreated HeLa cells were used.

\section{Fluorescent staining}

To examine the intracellular G-ROS (general reactive oxygen species) due to the PDT, we used a fluorescent reagent, $\mathrm{H}_{2}$ DCF-DA (Molecular Probes, Inc., Eugene, Oregon, USA), showing a fluorescence in response to the intracellular GROS (Zhang, 2008). $\mathrm{H}_{2}$ DCF-DA has a form which can easily permeate the cells. Once entered the cells, $\mathrm{H}_{2} \mathrm{DCF}-\mathrm{DA}$ is converted into the DCF by the deacetylation. This form cannot be released from the cells. The DCF is devoid of the fluorescence, but it is characterized by the fluorescence when it encounters the intracellular free ROS. Cells in the exponential growth phase were diluted using a culture medium to make sure that their concentration should be set to $10^{5}$ cells $/ \mathrm{ml}$. Then, the cells were aliquoted at a volume of $2 \mathrm{ml}$ in a cell culture plate, made of glass, whose floor had a diameter of $35 \mathrm{~mm}$ and a thickness of $0.17 \mathrm{~mm}$. This was followed by a culture in an incubator where a $5 \% \mathrm{CO}_{2}$ can be maintained for 24 hours. Then, the photosensitizer was 
diluted at varying concentrations $(0.5,1.1,2.3$ and $4.6 \mu \mathrm{g} / \mathrm{ml})$ using a cell culture medium and then added to the cells. This was followed by a culture in an incubator where a $5 \% \mathrm{CO}_{2}$ was maintained for six hours. This was followed by the irradiation with a $670-\mathrm{nm}$ diode laser $\left(1.7 \mathrm{~mW} / \mathrm{cm}^{2}, 1.6 \mathrm{~mJ} /\right.$ $\mathrm{cm}^{2}$ ). At 30 minutes, 1, 3, 6, 12 and 24 hours following the irradiation with a laser, $\mathrm{H}_{2}$ DCF-DA solution $(1 \mu \mathrm{M})$ melted in a DMEM culture medium was added to each well. This was followed by a 30-minute culture in an incubator where a temperature of $37^{\circ} \mathrm{C}$ and a $5 \% \mathrm{CO}_{2}$ were maintained for 30 minutes. Then, the culture medium was replaced by new one. This was immediately followed by a microscopic examination of the intracellular green fluorescence of G-ROS using a confocal microscope (Zeiss, 510 Meta, Germany) with an excitation at $488 \mathrm{~nm}$. Besides, the red-colored autofluorescence of 9-HpbD- $\alpha$ was examined using an excitation at $633 \mathrm{~nm}$. At the same locations, the fluorescence of G-ROS and 9-HpbD-a was photographed using a multi-track scan mode. All the photographic sessions were performed in the same condition. This was followed by a comparison of the relative intensity of fluorescence.

\section{MTT assay}

To examine the mechanisms of PDT using 9-HpbD- $\alpha$, the cells were treated with singlet oxygen quenchers (sodium azide and GSH) and hydroxyl radical scavenger (D-mannitol). Thus, MTT assay was used to examine the changes in the rate of cell viability following PDT. Cells in exponential growth phase were diluted using culture medium to make their concentration to be $10^{5}$ cells $/ \mathrm{ml}$. Then, the cells were seeded to a 96 -well plate at a volume of $100 \mu \mathrm{l}$ per well. This was followed by a 24 -hour culture in an incubator where a $5 \% \mathrm{CO}_{2}$ was maintained. Then $100 \mu \mathrm{l}$ of photosensitizer was added to a cell culture medium at a concentration of $18.75 \mu \mathrm{g} / \mathrm{ml}$. Its concentration was lowered using a 2-fold dilution. Each experimental group was added with D-mannitol (Sigma, USA) at concentrations of $40 \mathrm{mM}$ and $80 \mathrm{mM}$, sodium azide (Sigma, USA) at concentrations of $20 \mathrm{mM}$ and $40 \mathrm{mM}$ and GSH (Sigma, USA) at concentrations of $5 \mathrm{mM}$ and $10 \mathrm{mM}$. After incubation at $37^{\circ} \mathrm{C}$ for six hours, the culture medium was replaced with new one. Then the cells were irradiated with a $670-\mathrm{nm}$ diode laser $\left(1.7 \mathrm{~mW} / \mathrm{cm}^{2}\right.$ and $\left.1.6 \mathrm{~mJ} / \mathrm{cm}^{2}\right)$. After 12 hours, the culture medium was changed with fresh media and MTT [3-(4,5-dimethylthiazol-2-yl)-2,5-diphenyltetrazolium bromide] ( $2 \mathrm{mg} / \mathrm{ml}$, Sigma), melted in DPBS ( $\mathrm{pH} 7.3$ ), was added to each well at a volume of $50 \mu \mathrm{l}$. The cells were incubated in $37^{\circ} \mathrm{C}$ for 4 hours. The culture medium was removed and $150 \mu$ lof dimethylsulfoxide (DMSO; KANTO, Japan) was added. To well dissolve formazan, the sample was shaken with a microplate mixer (Amersham, UK) for 10-20 minutes. The absorbance was measured using a microplate reader (BIO-RAD 550, USA) at a wavelength of $540 \mathrm{~nm}$.

\section{Imidazole-RNO method}

To confirm the generation of singlet oxygen during the PDT with 9-HpbD- $\alpha$, the imidazole-RNO method was used (Kraljić 1986). The products were formed following the reaction between imidazole (Sigma, USA) and singlet oxygen, which induce the discoloration of RNO (N,N-dimethyl-4nitrosoaniline). This is a method where the formation of singlet oxygen is quantified by measuring the decrease in absorbance at a wavelength of $440 \mathrm{~nm}$. For the measurement of the optical absorbance, 9-HpbD- $100 \mu \mathrm{g} / \mathrm{ml}$, imidazole 8 $\mathrm{mM}$ and RNO $5 \mu \mathrm{M}$ were added in a cuvette. Then, during the irradiation with a $670-\mathrm{nm}$ laser for 55 minutes, the absorbance was measured at a wavelength of $440 \mathrm{~nm}$ for different time interval. 9-HpbD- $\alpha$ at $100 \mu \mathrm{g} / \mathrm{ml}$ and imidazole at $8 \mathrm{mM}$ were served as a blank solution and a diluting one, respectively. Thus, changes in the absorbance of RNO were confirmed.

\section{Results}

\section{The activity of G-ROS following the PDT}

The activity of G-ROS could be confirmed in presence of 9-HpbD- $\alpha$ at a concentration of $0.5 \mu \mathrm{g} / \mathrm{ml}$. 30 minutes after the PDT treatment, the activity of G-ROS was increased. One hour later, it was found to be very strong. Thereafter, the activity of G-ROS was decreased until 24 hours. In the presence of 9-HpbD- $\alpha$ at $1.1 \mu \mathrm{g} / \mathrm{ml}$ and $0.5 \mu \mathrm{g} / \mathrm{ml}$, we compared the activity of G-ROS at one hour following the PDT. This showed that it was relatively higher in the presence of 9-HpbD- $\alpha$ at $0.5 \mu \mathrm{g} / \mathrm{ml}$. Besides, in presence of $9-\mathrm{HpbD}-\alpha$ at $0.5 \mu \mathrm{g} / \mathrm{ml}$, a morphological observation of the cancer cells showed the formation of apoptotic bodies with the detachment of the cells (Fig. 1). This indicates that cancer cells might undergo apoptosis. Even in the presence of $9-\mathrm{HpbD}-\alpha$ at $1.1 \mu \mathrm{g} / \mathrm{ml}$, the activity of G-ROS could also be confirmed following the PDT. The degree of the expression of G-ROS was found to be very high one hour after the PDT as shown in the presence of $9-\mathrm{HpbD}-\alpha$ at $0.5 \mu \mathrm{g} / \mathrm{ml}$. Thereafter, the activity of G-ROS was confirmed to be gradually decreased until 24 hours. In addition, on a morphological examination of the cancer cells at the same concentrations of 9-HpbD- $\alpha$, the size of cancer cells was gradually decreased as the time elapsed until 24 hours. It was also shown that the cells were detached from the base of a cell culture plate (Fig. 2). In presence of 9-HpbD- $\alpha$ at 2.3 $\mu \mathrm{g} / \mathrm{ml}$, the activity of G-ROS could not be confirmed until 24 hours. Between 1 and 3 hours following the PDT, however, the activity of G-ROS could be confirmed to be very weak. On a morphological examination of the cells, until 24 hours following the PDT, the cell membrane was damaged while all the cancer cells were attached to the base of a cell culture plate. There were cancer cells showing an apoptosis rather than 


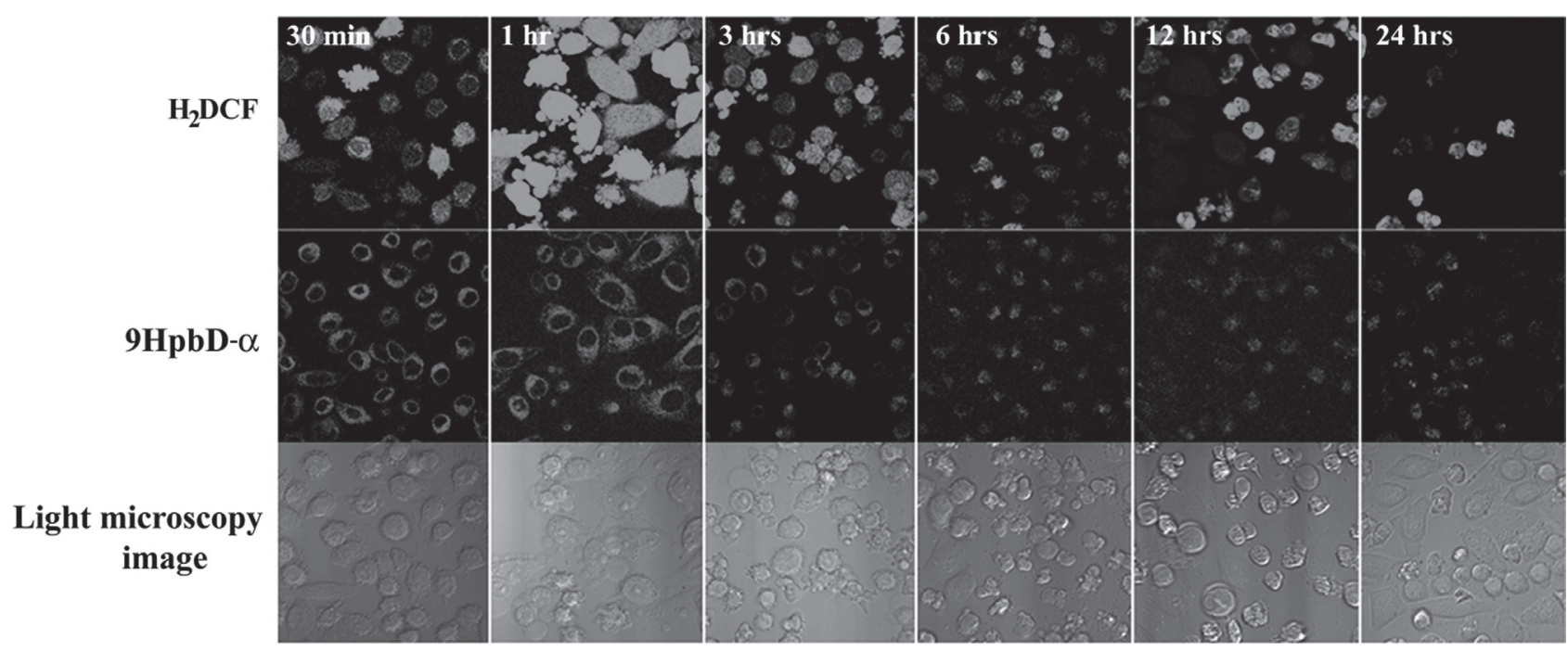

Figure 1. Time course image of G-ROS activity after PDT with $0.5 \mu \mathrm{g} / \mathrm{ml}$ 9-HpbD- $\alpha$ sensitized cells. The photosensitized cells were irradiated with a $670-\mathrm{nm}$ diode laser $\left(1.7 \mathrm{~mW} / \mathrm{cm}^{2}\right.$ and $\left.1.6 \mathrm{~mJ} / \mathrm{cm}^{2}\right)$. At varying time points (30 $\mathrm{min}, 1,3,6,12$ and $24 \mathrm{~h}$ ) after the laser irradiation, PDT-treated cells were stained with $1 \mu \mathrm{M} \mathrm{H}_{2}$ DCF-DA for 30 min. Stained cells were observed with a confocal microscope at the same configuration.

those with a normal shape (Fig. 3). Even in the presence of 9$\mathrm{HpbD}-\alpha$ at $4.6 \mu \mathrm{g} / \mathrm{ml}$, as shown in the presence of $9-\mathrm{HpbD}-\alpha$ at $2.3 \mu \mathrm{g} / \mathrm{ml}$, the activity of G-ROS could be confirmed between 30 minutes and 24 hours following the PDT. A morphological examination of the cancer cells also showed the same pattern as shown in the presence of $9-\mathrm{HpbD}-\alpha$ of $2.3 \mu \mathrm{g} / \mathrm{ml}$ (Fig. 4). The intracellular presence of a photosensitizer was confirmed based on the red-colored fluorescence of 9-HpbD- $\alpha$. In the experimental group the intracellular deposition of 9-HpbD- $\alpha$ was increased with the increasing concentration of 9-HpbD- $\alpha$.
In addition, in the presence of $9-\mathrm{HpbD}-\alpha$ at $2.3 \mu \mathrm{g} / \mathrm{ml}, 1.1 \mu \mathrm{g} / \mathrm{ml}$ and $0.5 \mu \mathrm{g} / \mathrm{ml}$, the degree of the intracellular deposition of 9-HpbD-a was decreased until 24 hours after the PDT. In the control group, there was a lack of the activity of G-ROS. Also in Group A, as shown in the control group, there was a lack of the activity of G-ROS. In Group B, the activity of G-ROS was confirmed to be very weak in comparison with Group A and the control group. As compared with other experimental groups, the activity of G-ROS was found to be very strong in the Group C (Fig. 5).

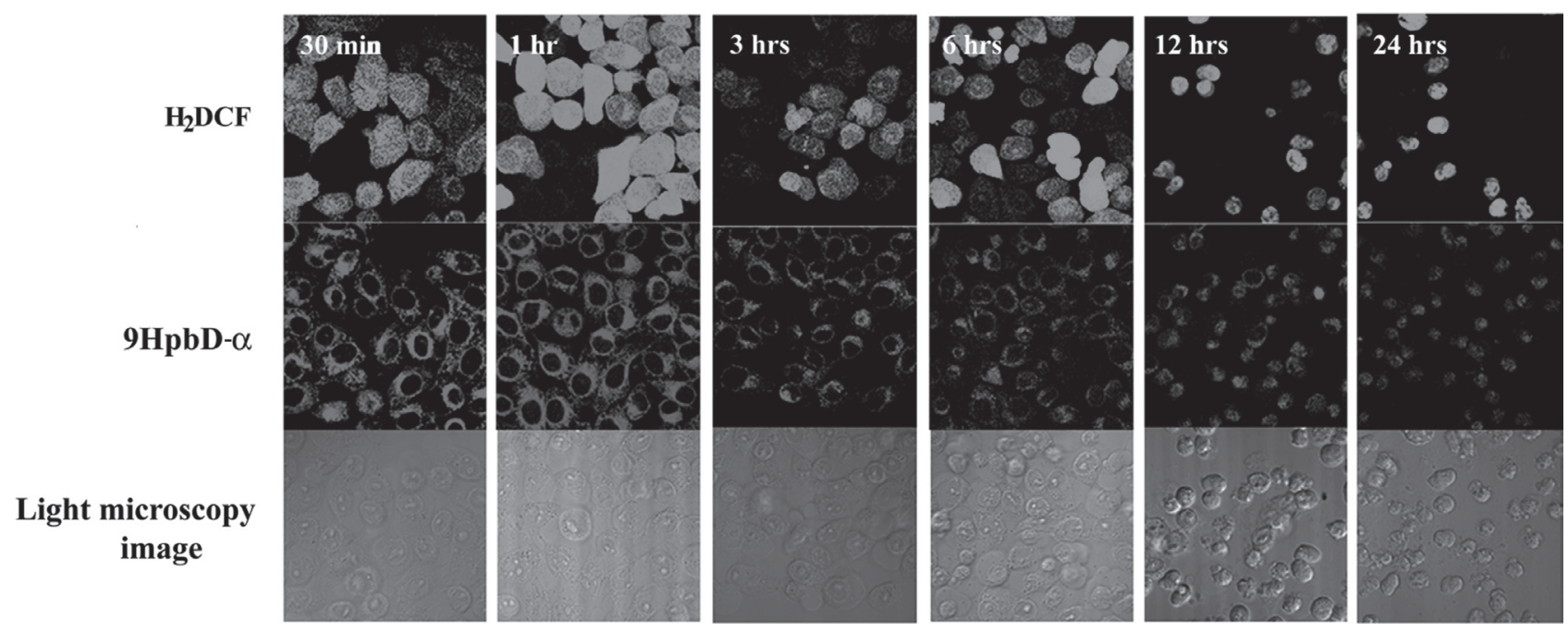

Figure 2. Time course image of G-ROS activity after PDT with $1.1 \mu \mathrm{g} / \mathrm{ml}$ 9-HpbD- $\alpha$ sensitized cells. The photosensitized cells were irradiated with a 670 -nm diode laser $\left(1.7 \mathrm{~mW} / \mathrm{cm}^{2}\right.$ and $\left.1.6 \mathrm{~mJ} / \mathrm{cm}^{2}\right)$. At varying time points (30 $\mathrm{min}, 1,3,6,12$ and $24 \mathrm{~h}$ ) after the laser irradiation, PDT-treated cells were stained with $1 \mu \mathrm{M} \mathrm{H}_{2}$ DCF-DA for $30 \mathrm{~min}$. Stained cells were observed with a confocal microscope at the same configuration. 


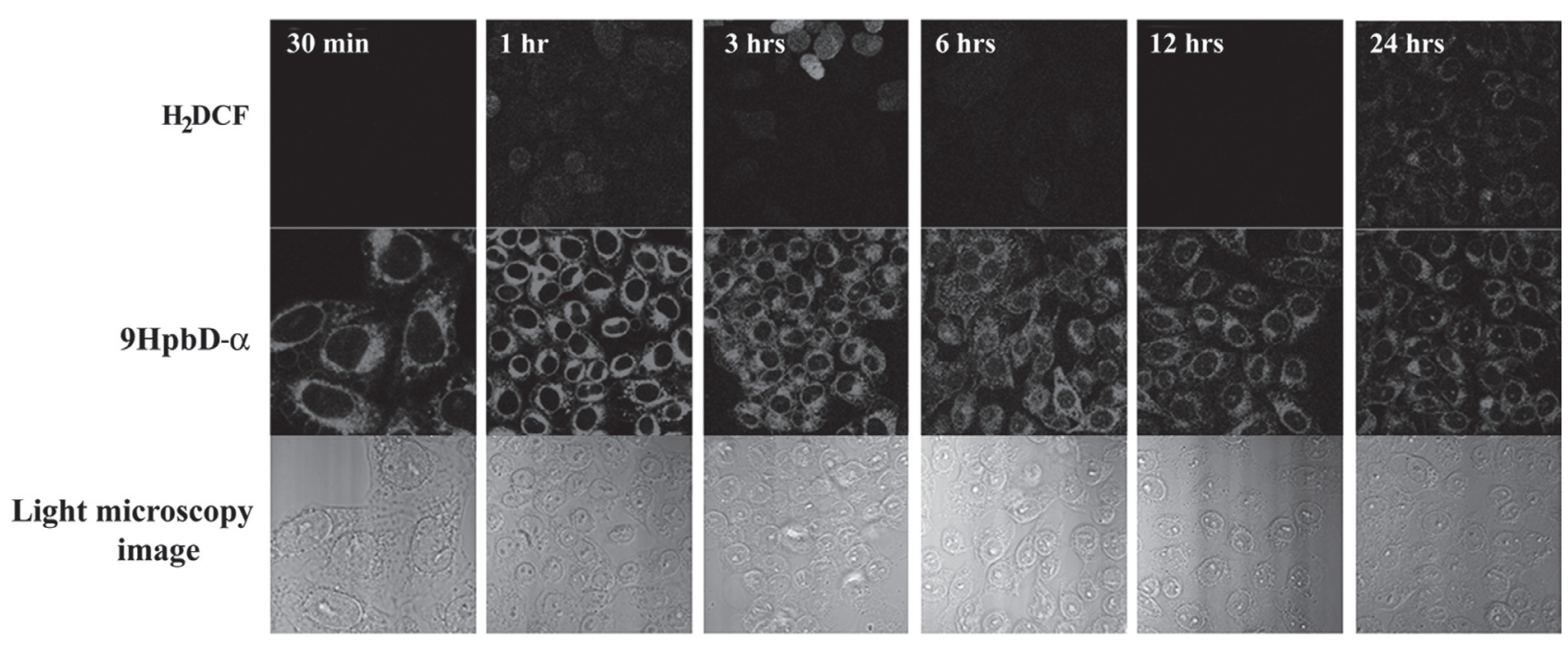

Figure 3. Time course image of G-ROS activity after PDT with $2.3 \mu \mathrm{g} / \mathrm{ml}$ 9-HpbD- $\alpha$ sensitized cells. The photosensitized cells were irradiated with a 670 -nm diode laser $\left(1.7 \mathrm{~mW} / \mathrm{cm}^{2}\right.$ and $1.6 \mathrm{~mJ} / \mathrm{cm}^{2}$ ). At varying time points (30 min, 1, 3, 6, 12 and $24 \mathrm{~h}$ ) after the laser irradiation, PDT-treated cells were stained with $1 \mu \mathrm{M} \mathrm{H}_{2}$ DCF-DA for $30 \mathrm{~min}$. Stained cells were observed with a confocal microscope at the same configuration.

\section{The mechanisms of PDT: Type I reaction}

We compared the percentage of cell viability of Group D with the control group. This showed that percentage of cell viability was $12.8 \pm 0.06 \%$ and $12.6 \pm 0.5 \%$ in Group C and Group D (40 mM D-mannitol), respectively. Besides, the rate of cell viability was $12.3 \pm 0.5 \%$ in Group D (80 mM Dmannitol) (Fig. 6). Furthermore, we also compared the rate of cell viability between Group C and Group D. This showed that D-mannitol had no effects on the rate of cell viability during the PDT. These results indicate not only that hydroxyl radicals based on the mechanisms of PDT using 9-HpbD-a had no effects on the cytotoxicity but also that Type I reaction had no effects on the PDT using 9-HpbD- $\alpha$.

\section{The mechanism of PDT: Type II reaction}

We indirectly compared the degree of synthesis of singlet oxygen between Group E or Group F and the control group. This showed that it was $15.4 \pm 0.12 \%$ in Group C and

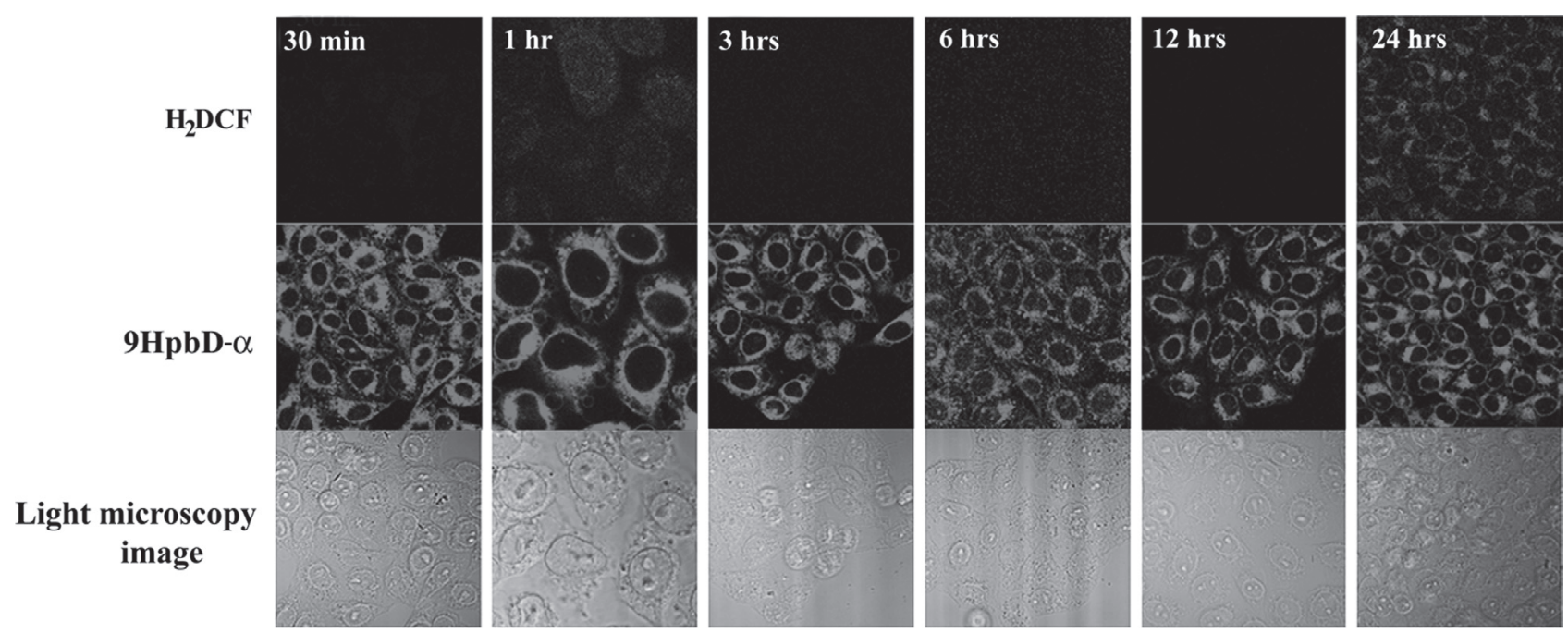

Figure 4. Time course image of G-ROS activity after PDT with $4.6 \mu \mathrm{g} / \mathrm{ml}$ 9-HpbD-a sensitized cells. The photosensitized cells were irradiated with a $670-\mathrm{nm}$ diode laser $\left(1.7 \mathrm{~mW} / \mathrm{cm}^{2}\right.$ and $1.6 \mathrm{~mJ} / \mathrm{cm}^{2}$ ). At varying time points (30 min, 1, 3, 6, 12 and $24 \mathrm{~h}$ ) after the laser irradiation, PDT treated cells were stained with $1 \mu \mathrm{M} \mathrm{H}_{2}$ DCF-DA for $30 \mathrm{~min}$. Stained cells were observed with a confocal microscope at the same configuration. 


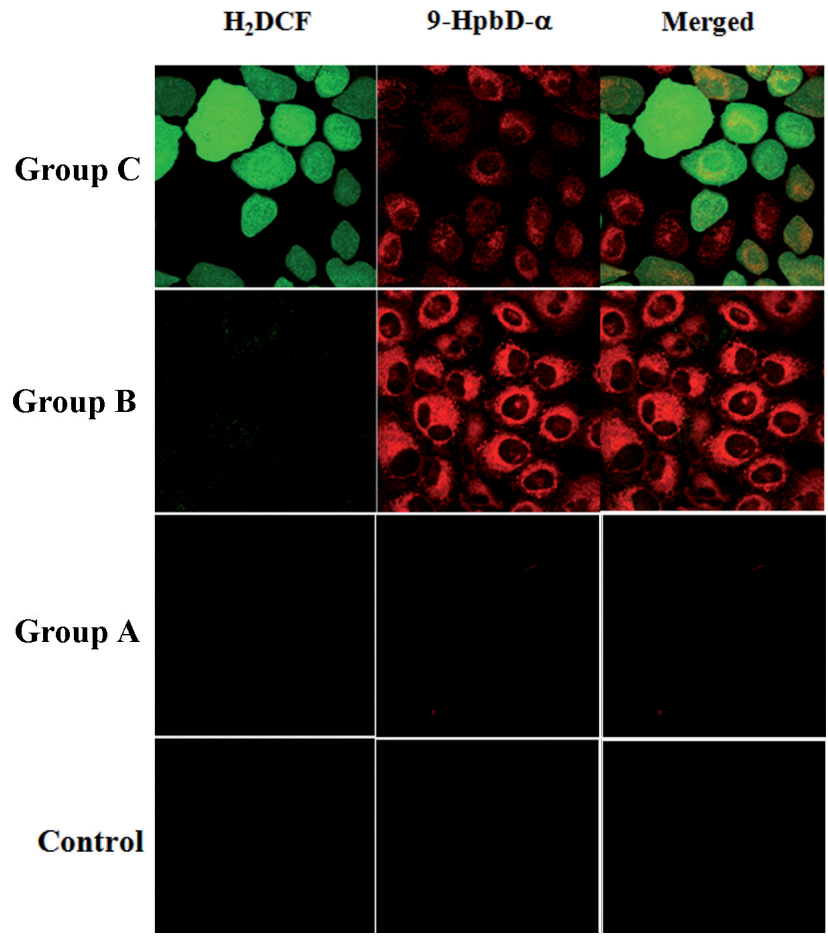

Figure 5. Images of HeLa cell lines stained with $1 \mu \mathrm{M} \mathrm{H} \mathrm{H}_{2} \mathrm{DCF}-\mathrm{DA}$ for different groups of treatment. Group A - laser monotherapy, Group B - 9-HpbD- $\alpha$ at a concentration of $1.1 \mu \mathrm{g} / \mathrm{ml}$, Group C PDT with 9-HpbD- $\alpha$ at a concentration of $1.1 \mu \mathrm{g} / \mathrm{ml}$ and untreated controls. Fluorescence intensity in the PDT group was highly increased.

$18.1 \pm 0.87 \%$ in Group E $(20 \mathrm{mM}$ sodium azide $)$. In addition, it was $26.1 \pm 0.06 \%$ in Group E (40 mM sodium azide). In the Group C, it was increased by approximately $30 \%$ as compared with those treated with $20 \mathrm{mM}$ sodium azide following the PDT. In Group C, it was increased by approximately $11 \%$ as compared with Group E (40 mM sodium azide). This reached a statistical significance $p<$ 0.05 . This is also accompanied by the decreased apoptosis because of singlet oxygen which was formed during the PDT using 9-HpbD-a in Group E (Fig. 7). Besides, the rate of cell viability was $16.2 \pm 6.4 \%$ in Group C and $54.4 \pm$ $1.83 \%$ in Group F (5mM GSH). In addition, it was $55.4 \pm$ $3.79 \%$ in Group F (10 mM GSH). We compared the rate of cell viability between Group C and Group F (5 mM GSH). This showed that it was increased by approximately $38 \%(p<0.05)$. In addition, we also compared the rate of the cell viability of Group F (10 mM GSH) with Group C. This showed that it was increased by approximately $39 \%$. This reached a statistical significance (Fig. 8) $(p<0.05)$. There was a similarity in the pattern between GSH andsodium azide, thus indicating that the degree of apoptosis was decreased following the treatment with GSH. This is because singlet oxygen was formed during the PDT using 9-HpbD- $\alpha$. During the PDT using 9-HpbD- $\alpha$, the synthesis of singlet oxygen was confirmed. It was also shown that singlet oxygen was directly involved in the cytotoxicity. These results indicate that Type II reaction is mainly involved in the apoptosis as the mechanism of PDT.

\section{The synthesis of singlet oxygen}

To confirm the presence of singlet oxygen which is formed during the PDT using 9-HpbD- $\alpha$, the measurement was done using the methods of imidazole-RNO (N,N-dimethyl-4-nitrosoaniline). Following the measurement, the initial $\mathrm{OD}_{440}$ (OD: optical density) in both 9-HpbD- $\alpha$ and imidazole-RNO solution was measured as $1.04 \pm 0.001$. Thereafter, with the irradiation with a 670 -nm diode laser, the $\mathrm{OD}_{440}$ was measured over time. This showed that the $\mathrm{OD}_{440}$ was $0.87 \pm 0.001$ at 10 minutes after the irradiation, $0.75 \pm 0.001$ at 20 minutes after the irradiation, $0.63 \pm 0.0005$ at 30 minutes after the irradiation, $0.53 \pm 0.001$ at 40 minutes after the irradiation and $0.44 \pm 0.001$ at 50 minutes after the irradiation. These results indicate that the optical density $\left(\mathrm{OD}_{440}\right)$ was decreased as the time of irradiation elapsed. But there is no significant change in the control group. At 55 minutes of time interval, absorbance at $440 \mathrm{~nm}$ decreased to $0.96 \pm 0.001$ which is a clear indication that the synthesis of singlet oxygen in negative control is negligible (Fig. 9). These results have confirmed not only that the synthesis of singlet oxygen during the PDT using 9-HpbDa but also that the amount of synthesized singlet oxygen was also increased as the time of irradiation elapsed.

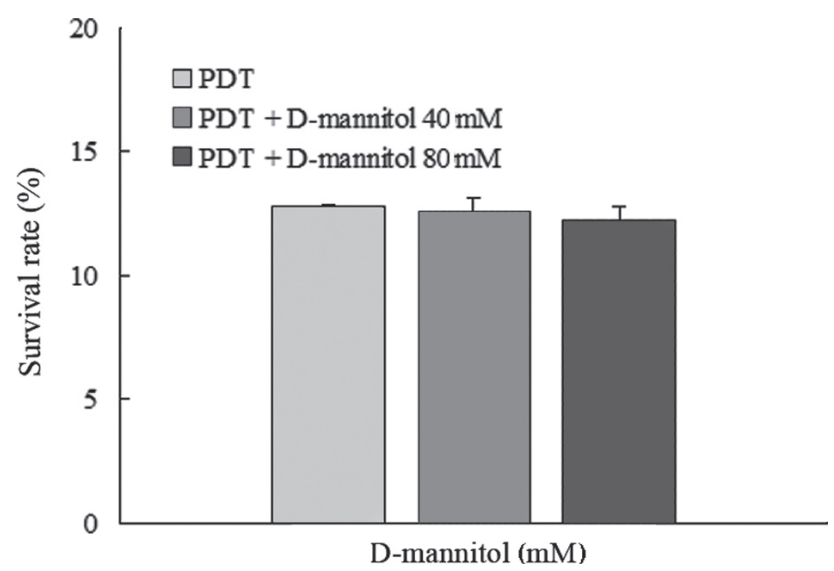

Figure 6. Effects of D-mannitol on the cell survival following the PDT. $40 \mathrm{mM}$ and $80 \mathrm{mM}$ of D-mannitol were added to the cells at the same time as the addition of 9-HpbD- $\alpha(0.5 \mu \mathrm{g} / \mathrm{ml})$. After 4hours of incubation, culture media were replaced with the fresh ones. This was followed by the laser treatment using a $670-\mathrm{nm}$ diode laser $\left(1.7 \mathrm{~mW} / \mathrm{cm}^{2}\right.$ and $1.6 \mathrm{~mJ} / \mathrm{cm}^{2}$ ). The treated cells were incubated for 24 hours, for which the MTT assay was carried out to quantify the viability of cells. 


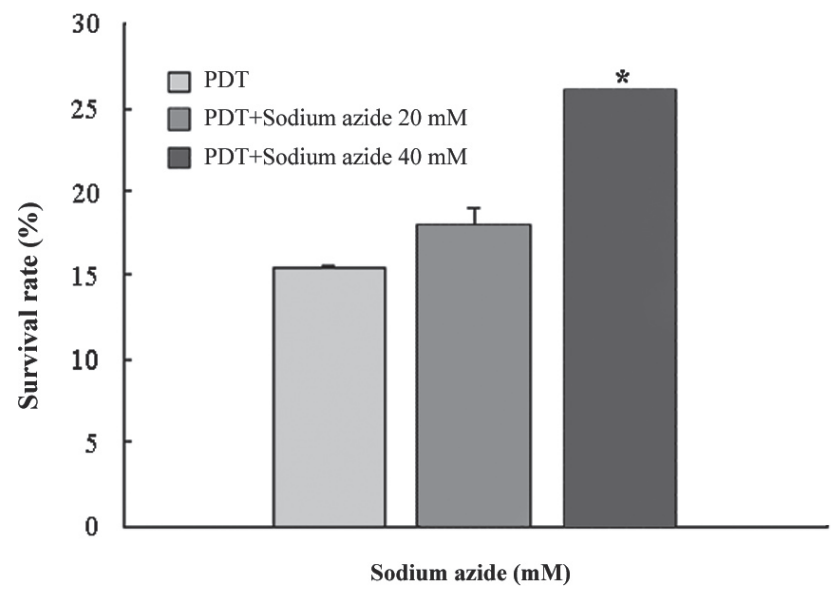

Figure 7. Effects of sodium azide on the cell survival following the PDT. $20 \mathrm{mM}$ and $40 \mathrm{mM}$ of sodium azide were added to the cells at the same time as the addition of $9-\mathrm{HpbD}-\alpha(0.5 \mu \mathrm{g} / \mathrm{ml})$. After a 4 hour incubation, culture media were changed with the fresh ones. This was followed by the laser treatment using a 670 -nm diode laser $\left(1.7 \mathrm{~mW} / \mathrm{cm}^{2}\right.$ and $\left.1.6 \mathrm{~mJ} / \mathrm{cm}^{2}\right)$. The treated cells were incubated for 24 hours, for which the MTT assay was carried out to quantify the viability of cells $\left({ }^{*} p<0.01 v s\right.$. PDT by two-way ANOVA test).

\section{Discussion}

A photosensitizer is commonly used during the PDT, and it increases the activity of light with a certain wavelength and thereby binds to the oxygen within the body. This eventually leads to the apoptosis. In the current study, we used 9-HpbD-a as a photosensitizer. It has been developed from pheophytina, prepared by the removal of metal ion from chlorophyll-a of Spirulina platensis, blue algae, and pheobide-a, prepared from the hydrolysis of phytol group of pheophytin-a. This is a photosensitizer that can overcome the disadvantages of conventional types of photosensitizer HpD. That is, it can shorten the time of in vivo excretion and can thereby prevent the in vivo accumulation. Besides, if the maximal absorption wavelength of a photosensitizer be increased, the laser would be selected to be appropriate for this photosensitizer. In the lasers whose wavelength is relatively higher in the range of visible light, the depth of tissue infiltration should be increased. This would eventually enhance the effects of PDT. Conventional types of $\mathrm{HpD}$ photosensitizer show a maximal activity at a wavelength range of $630 \mathrm{~nm}$. The maximal absorption wavelength of $9-\mathrm{HpbD}-\alpha$ is $670 \mathrm{~nm}$. It is therefore advantageous in that a higher wavelength can be used as compared with conventional types of a photosensitizer.

As the mechanisms of PDT, the ROS is produced by the reactions between the photo-activated photosensitizer molecules and the oxygen molecules within the body. These mechanisms are divided into Type I reaction and Type II one. A photosensitizer absorbs the light energy, by which it is activated from the ground state $\left(\mathrm{S}_{0}\right)$ to the single state $\left(\mathrm{S}_{1}\right)$ and then converted to the triplet state $\left(\mathrm{T}_{1}\right)$. In the triplet state, it undergoes two types of reactions. In other words, Type I reaction is referred to as that where free radicals or radical ions are produced by the abstract reaction or electron transfer reaction between the activated photosensitizer and hydrogen atom. These substances representatively include hydroxyl radicals or superoxide anions. Type II reaction is referred to as the energy transfer reaction between the activated photosensitizer and oxygen molecule, where the singlet oxygen is produced. It has generally been reported that Type II reaction accounts for a greater part of the mechanisms of PDT. It is also known that it predominantly occurs in the hypoxic state or polar environment (Foote 1991; Sharman et al. 1999). Also in the current study, the activity of ROS was confirmed within the cells during the PDT using the 9-HpbD- $\alpha$. Besides, the degree of the activity of ROS was found to be relatively higher in the intracellular domain where the photosensitizer was accumulated. According to previous studies about the PDT using 9-HpbD- $\alpha$, a higher-dose and a lower-dose of 9-HpbD-a triggered the occurrence of cell necrosis and apoptosis, respectively (Ahn 2002). It has also been presumed that the intracellular expression of ROS is associated with two types of cell necrosis as described herein. Following the experiment, the degree of the intracellular activity of ROS was found to be relatively higher in such a condition that the apoptosis occurs. Following the treatment with a higher-dose of 9-HpbD- $\alpha$ by which the cell necrosis occurs, however, there was a lack of the activity of ROS. Besides, one of the scavengers of hydroxyl

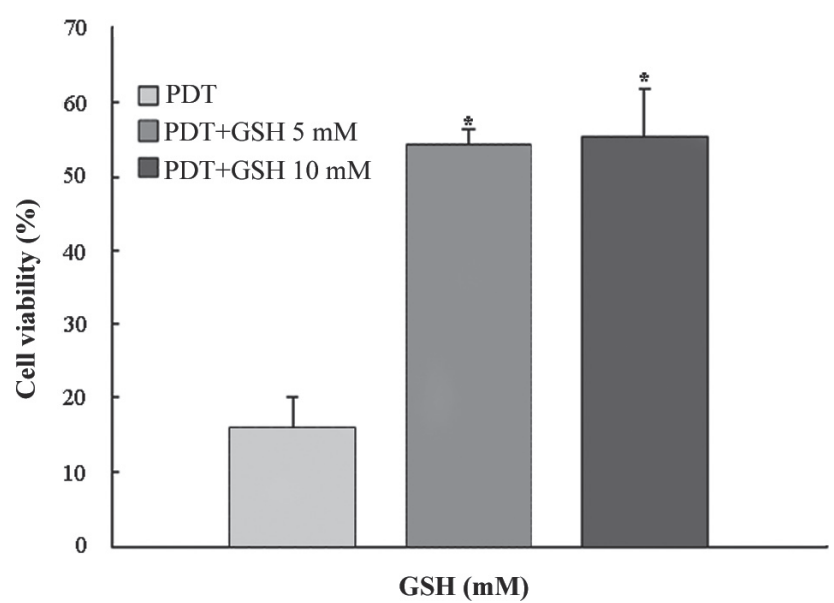

Figure 8. Effects of GSH on the cell survival following the PDT. 5 $\mathrm{mM}$ and $10 \mathrm{mM}$ of GSH were added to the cells at the same time as the addition of $9-\mathrm{HpbD}-\alpha(0.5 \mu \mathrm{g} / \mathrm{ml})$. After a 4-hour incubation, culture media were changed with the fresh ones. This was followed by the laser treatment using a $670-\mathrm{nm}$ diode laser $\left(1.7 \mathrm{~mW} / \mathrm{cm}^{2}\right.$ and $1.6 \mathrm{~mJ} / \mathrm{cm}^{2}$ ). The treated cells were incubated for 24 hours, for which the MTT assay was carried out to quantify the viability of cells ${ }^{*} p<0.01 v s$. PDT by two-way ANOVA test). 


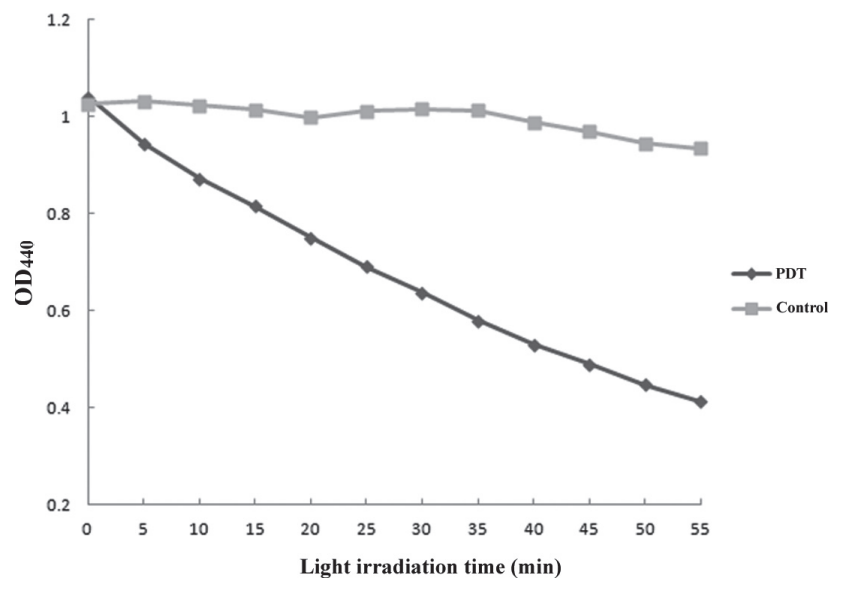

Figure 9. The synthesis of singlet oxygen by the photoactivation with $9-\mathrm{HpbD}-\alpha$. For the detection of singlet oxygen, 9-HpbD- $\alpha$ solution $(100 \mu \mathrm{g} / \mathrm{ml})$ was added to imidazole $(8 \mathrm{mM})$ plus RNO $(5 \mu \mathrm{M})$ solution. In this solution, the decreased absorbance was measured at a wavelength of $440 \mathrm{~nm}$ to detect the RNO bleaching during the irradiation with a $670-\mathrm{nm}$ diode laser.

radicals, D-mannitol, had no effects on the apoptosis during the PDT using 9-HpbD- $\alpha$. But sodium azide and GSH, both of which are singlet oxygen quencher, reduced the apoptosis during the PDT. It was also shown that single oxygen was produced following the PDT. These results strongly indicate that the major mechanisms of the PDT using 9-HpbD- $\alpha$ are based on Type II reaction, in which singlet oxygen is involved, rather than Type I reaction, in which hydroxyl radicals.

Our results showed not only that the activity of ROS is involved in the PDT using 9-HpbD- $\alpha$ in human uterine cervical cancer cell lines but also that the mechanisms of PDT are based on Type II reaction where the singlet oxygen is involved.

\section{References}

Abdulla M., Haeger-Aronson B. (1971): ALA-dehydratase activation by zinc. Enzyme 12, 708-710

Ahn J. C. (2002): The anticancer effect and mechanism of photodynamic therapy using 9-hydroxypheophorbide-alpha and $660 \mathrm{~nm}$ diode laser on human squamous carcinoma cell line. Dankook University publication, Dankook University (Korea), $1-50$

Ana P., Castano P. M., Hamblin M. R. (2006): Photodynamic therapy and anti-tumor immunity. Nature Reviews Cancer 6, 535-545 http://dx.doi.org/10.1038/nrc1894

Desesso J. M., Scialli A. R., Goeringer G. C. (1994): D-mannitol, a specific hydroxyl free radical scavenger, reduces the developmental toxicity of hydroxyurea in rabbits. Teratology 49, 248-259 http://dx.doi.org/10.1002/tera.1420490404
Devasagayam T. P., Sundquist A. R., Di Mascio P., Kaiser S., Sies H. (1991):Activity of thiols as singlet molecular oxygen quenchers. J. Photochem. Photobiol. B 9, 105-116 http://dx.doi.org/10.1016/1011-1344(91)80008-6

Dougherty T. J., Gomer C. J., Henderson B. W., Jori G., Kessel D., Korbelik M. (1998): Photodynamic therapy. J. Natl. Cancer Inst. 90, 889-905 http://dx.doi.org/10.1093/jnci/90.12.889

Dougherty T. J. (2002): An update on photodynamic therapy applications. J. Clin. Laser Med. Surg. 20, 3-7 http://dx.doi.org/10.1089/104454702753474931

Foote C. S. (1991): Definition of type I and type II photosensitized oxidation. Photochem. Photobiol. 54, 659 http://dx.doi.org/10.1111/j.1751-1097.1991.tb02071.x

Grether-Beck S., Olaizola-Horn S., Schmitt H., Grewe M., Jahnke A., Johnson J. P., Briviba K., Sies H., Krutmann J. (1996): Activation of transcription factor AP-2 mediates UVA radiationand singlet oxygen-induced expression of the human intercellular adhesion molecule 1 gene. Proc. Natl. Acad. Sci. U.S.A. 93, 14586-14591 http://dx.doi.org/10.1073/pnas.93.25.14586

Kraljić I. (1986): Detection of singlet oxygen and its role in dyesensitized photooxidation in aqueous and micellar solutions. Biochimie 68, 807-811 http:dx.doi.org/10.1016/S0300-9084(86)80096-7

Lee W. Y., Park J. H., Kim B. S., Han M. J., Hahn B. S. (1990): Chlorophyll derivatives $(\mathrm{CpD})$ extracted from silk worm excreta are specifically cytotoxic to tumor cells in vitro. Yonsei Med. J. 31, 225-233

Moan J., Pettersen E. O., Christensen T. (1979): The Mechanism of photodynamic inactivation of human cells in vitro in the presence of haematoporphyrin. Br. J. Cancer 39, 398-407 http://dx.doi.org/10.1038/bjc.1979.72

Nelson J. S., Liaw L. H., Berns M. W. (1987): Tumor destruction in photodynamic therapy. Photochem. Photobiol. 46, 829-835 http://dx.doi.org/10.1111/j.1751-1097.1987.tb04855.x

Oleinick N. L., Evans H. H. (1998): The photobiology of photodynamic therapy: cellular targets and mechanisms. Radiat. Res. 150, S146-156 http://dx.doi.org/10.2307/3579816

Peng Q., Berg K., Moan J., Kongshaug M., Nesland J. M. (1997): 5-Aminolevulinic acid-based photodynamic therapy: Principles and experimental research. Photochem. Photobiol. 65, 235-251 http://dx.doi.org/10.1111/j.1751-1097.1997.tb08549.x

Rosenthal I. (1991): Phthalocyanines as photodynamic sensitizers. Photochem. Photobiol. 53, 859-870

Sharman W. M., Allen C. M., Van Lier J. E. (1999): Photodynamic therapeutics: basic principles and clinical applications. Drug Discov. Today 4, 507-517 http://dx.doi.org/10.1016/S1359-6446(99)01412-9

Zhang J., Xing D., Gao X. (2008): Low-power laser irradiation activates Src tyrosine kinase through reactive oxygen speciesmediated signaling pathway. J. Cell. Physiol. 217, 518-528 http://dx.doi.org/10.1002/jcp.21529

Received: March 12, 2012

Final version accepted: June 6, 2012 